\title{
Changing Preference of One- Vs. Two-Stage Implant Placement in Partially Edentulous Individuals: An 18-Year Retrospective Study
}

\author{
Liat Chaushu ${ }^{1,+}{ }^{\circ}$, Sarit Naishlos ${ }^{2}$, Ofir Rosner ${ }^{3}$, Eran Zenziper ${ }^{3}$, Ari Glikman ${ }^{3}$, David Lavi ${ }^{3}$, \\ Irit Kupershmidt $^{3}$, Helena Zelikman ${ }^{3}$, Gavriel Chaushu ${ }^{4, *}$ and Joseph Nissan ${ }^{3}$ \\ 1 Department of Periodontology and Implant Dentistry, School of Dental Medicine, Tel Aviv University, \\ Tel-Aviv 69978, Israel; liat.natanel@gmail.com \\ 2 Department of Pedodontology, School of Dental Medicine, Tel Aviv University, Tel-Aviv 69978, Israel; \\ Naishloss@mail.tau.ac.il \\ 3 Department of Oral Rehabilitation, School of Dental Medicine, Tel Aviv University, Tel-Aviv 69978, Israel; \\ rosnerop@yahoo.com (O.R.); eranzen@gmail.com (E.Z.); glidmana@tauex.tau.ac.il (A.G.); \\ lavidav@tauex.tau.ac.il (D.L.); ikuper@post.tau.ac.il (I.K.); helenap@tauex.tau.ac.il (H.Z.); \\ nissandr@gmail.com (J.N.) \\ 4 Department of Oral \& Maxillofacial Surgery, School of Dental Medicine, Tel Aviv University, Tel-Aviv 69978, Israel \\ * Correspondence: gavrielce@clalit.org.il \\ + Liat Chaushu and Sarit Naishlos, equally contributed to the study.
}

Received: 2 September 2020; Accepted: 5 October 2020; Published: 12 October 2020

\begin{abstract}
The purpose of the present long-term retrospective study was to assess the changing preference of one- vs. two-stage implant placement in partially edentulous individuals. The clinical outcome measures were one- vs. two-stage implant placement, implant survival, and gingival index. The radiological outcome measure was crestal bone loss. Other recorded information included gender, age, implant characteristics (brand, type, length, diameter) and implant location (maxilla/mandible). A total of 393 implants in 111 patients were included. The results revealed that there were no significant demographic differences between the one- and two-stage implant placement groups. There was a preference for one-stage surgery when wide diameter implants were used and when the number of implants per patient was $\leq 3$. The mandible was the major implant site in the one-stage surgery group. Crestal bone loss and gingival index were similar for the two groups in both the short and long term. It can be concluded that lack of any long-term differences in implant survival, crestal bone loss and gingival health around implants after one- or two-stage implant placement promoted a significant change over 18 years, increasing to $50 \%$ the prevalence of one-stage surgery.
\end{abstract}

Keywords: dental implants; one-stage surgery; two-stage surgery; implant survival; surgical preference

\section{Introduction}

The possibility of implant-supported restoration first appeared in the 1970s [1]. The use of dental implants is undoubtedly the most important breakthrough in dentistry for the last 30 years [2]. One of the main goals of clinicians is to hone their abilities in assigning an accurate prognosis and in developing a predictable surgical protocol. In the era of evidence-based implant dentistry, long-term studies allow us to reexamine our treatment approaches and decide which minimal morbidity and best outcome treatment protocols to pursue. Implant dentistry has gained great acceptance because of its high success rates; now, the critical question is whether we can minimize the morbidity associated with the procedure and shorten the total treatment time, without decreasing the success rate. 
Dental implants were traditionally inserted into the bone by means of a two-stage surgical protocol ad modem Brånemark, in order to reduce the risk of failure. Primary stability of the implant in the bone and the absence of its mobility during the healing period were considered two key factors essential to success [3]. Implant mobility during the healing period may lead to lack of osseointegration, similar to non-healing following fragment movement in bony fractures [4]. The two-stage surgical approach significantly reduces the risk of transfer of unwanted forces to the implant/bone interface during healing, however, a second surgical intervention is required to connect the implant's healing caps. In addition, this second surgical intervention hinders the continuation of rehabilitation for several weeks required for complete healing of the soft tissue around the healing caps [2].

Simultaneously, Straumann AG. (Basel, Switzerland) developed an implant system using a single surgical stage [5]. That system had an implant neck around $3 \mathrm{~mm}$ longer than the implants used for the two-stage system. The edge of the rough surface, located about $3 \mathrm{~mm}$ apical to the implant edge (and not the tip of the implant) was placed at the height of the alveolar ridge. This obviated the need for a healing cap whose function was now carried out by the cover screw with the longer neck of the implant. In this one-stage method, the surgical flap was sutured around the implant neck, thus avoiding the need for a second surgical intervention. Long-term studies have demonstrated the potential of reaching an even higher rate of success with this method [6,7]. Additional controlled studies [8-14], including implant brands and types using a two-stage surgical protocol similar to Brånemark system with internal or external hex, compared one- vs. two-stage implant placement also showed that one-stage implants yielded high success rates.

The purpose of the present study was to assess the changing surgeons' preference of one- vs. two-stage implant placement in partially edentulous individuals over a period of 18 years. The null hypothesis was that one-stage preference increased over time.

\section{Materials and Methods}

\subsection{Subjects}

The study population included 111 individuals diagnosed as being partially edentulous. The treatment plan chosen for them between 1992-2010 at the Department of Prosthodontics, School of Dental Medicine, Tel Aviv University, was implant-supported restoration. The records of all the dental school patients are archived for educational, research and medicolegal purposes. In order to have a long-term follow-up, implant placement in 2010 was chosen as the last year included. Follow up continued yearly up to 2018. All procedures were fully explained to the patients who signed an informed consent, and the Ethics Committee of the Tel Aviv University approved the study protocol. Protection of humans was clearly described and complied with national and international protection guidelines. Protections meet or exceeds the current WMA Declaration of Helsinki-Ethical Principles for Medical Research Involving Human Subjects.

\subsection{Study Design}

Retrospective non-random, observational, cohort long-term study. The study inclusion criteria were: cone beam computerized tomography (CBCT), flap procedure, two experienced surgeons, date of implant placement between 2000-2010, partially edentulous, healed implantation sites, sufficient keratinized gingiva ( $>2 \mathrm{~mm}$ on either side of incision), fixed partially restoration, informed consent to undergo implant-supported restoration, generally good health, and available periapical radiographs performed with a film holder (Dentsply Rinn, Elgin Rinn Corporation, XCP). The exclusion criteria were gingival grafts; irradiation in the head and neck area; uncontrolled diabetes; pregnant or nursing, substance abuse; immunosuppressed or immunocompromised patients; treatment with oral or IV bisphosphonates; psychiatric therapy; untreated periodontal disease; healed sites (at least 3 months after teeth extraction); severe bruxism or clenching; poor oral hygiene and motivation (full mouth bleeding on probing and full mouth plaque index $>25 \%$; current smoking (over 10 cigarettes 
per day); immediate placement; immediate loading; implant design (tissue level). The primary outcome parameter was fraction of technique preference over the years. The secondary outcome parameters included clinical measures as implant survival, radiological measure-crestal bone loss and gingival index [15]. The gingival index is used for the assessment of prevalence and severity of gingivitis. Score $0=$ Normal gingiva; Score $1=$ Mild inflammation-slight change in color, slight edema. No bleeding on probing; Score 2 = Moderate inflammation—redness, edema, glazing. Bleeding on probing; Score 3 = Severe inflammation -marked redness and edema, ulceration. Tendency toward spontaneous bleeding.

Additional information that was retrieved from the patients' files included gender, age, implant characteristics (type, length, diameter) and implant location (maxilla/mandible).

\subsection{Methods}

Measurements of crestal bone loss at the mesial and distal parts of the implant were made by computer analysis using periapical radiographs, similar to the method of measurement described by Turkyilmaz et al. [16]. Namely, periapical radiographs taken immediately after implantation were used as baseline. Available last follow-up periapical radiographs were used to assess the amount of marginal bone loss. All images were available in their actual size. For each implant included in the study, baseline and last follow-up radiographs were compared using Image-J (Image Processing and Analysis Software in JAVA). Initial crestal bone height was measured from a reference point, namely implant-abutment junction, to the nearest bone-implant interface, namely, the adjacent crestal bone-implant contact (mesial and distal). Measurements were compared with the crestal bone height on the radiograph obtained at last follow-up. The difference between the two measurements was defined as marginal bone loss. The length of the implant was used to cancel vertical X-ray distortion.

\subsection{Statistical Analysis}

All the data were assessed by an independent statistical consultant for statistical differences using the $t$-test for age, implant diameter, implant length the $\chi^{2}$-test to compare gender distribution, marginal bone loss, smoking status, gingival index and Pearson's correlation to test the correlation between the number of implants and the surgical technique and the correlation between maxilla/mandible implant location and the surgical technique. The differences were considered significant if the $p$-values were less than 0.05 .

\section{Results}

\subsection{Implant Description and Distribution}

The study group consisted of 111 individuals, including 48 (43\%) men and 63 (57\%) women whose age range was $19-77$ years, mean $54 \pm 15$ years. Twenty-three (21\%) were current smokers. Fifteen individuals had undergone both dental implant methods in different areas of the jaw. A total of 126 areas were included in the study: the two-stage surgical approach was used at $74(59 \%)$ areas and the one-stage surgical approach was used at $52(41 \%)$ areas. There was a total of 393 implants, of which $228(58 \%)$ were located in the mandible and $165(42 \%)$ were located in the maxilla. Four implant brands and five implant types were used. All implants had bone level insertion indication. Two types had external hex: Branemark system MK II 47/393 (12\%) and 3I Osseotite implant 50/393 (13\%). Three types had internal hex: Screw vent, Zimmer Dental 110/393 (28\%); 3I Certain 49/393 (12\%); Seven, MIS 137/393 (35\%) The implant diameter ranged from $3.25 \mathrm{~mm}$ to $6 \mathrm{~mm}$ (average $4.1 \pm 0.4 \mathrm{~mm}$ ). The implant length ranged from $8 \mathrm{~mm}$ to $16 \mathrm{~mm}$ (average $12.3 \pm 1.5 \mathrm{~mm}$ ). Follow-up time ranged from 12 to 181 months (average $36 \pm 38$ months). The gingival index at the last follow-up was 0 for 279 (71\%) implants and 1 for the remaining $114(29 \%)$ implants. Crestal bone loss ranged from $0 \mathrm{~mm}$ to $8 \mathrm{~mm}$, and the average crestal bone loss for the study was $1 \pm 0.9 \mathrm{~mm}$ in both the mesial and distal implant areas. 


\subsubsection{One-Stage Surgery}

Fifty-two individuals, comprised of 23 (44\%) men and 29 (56\%) women, underwent one-stage surgery that involved a total of 140 implants. Their age range was 22-74 years (mean $54 \pm 14.8$ ), and $8(15 \%)$ were current smokers. Of the 140 implants, $110(78 \%)$ were in the lower jaw and $30(22 \%)$ in the upper jaw. The implant diameter ranged from $3.5 \mathrm{~mm}$ to $6 \mathrm{~mm}$ (mean $4.3 \pm 0.5 \mathrm{~mm}$ ), and the implant length ranged from $10 \mathrm{~mm}$ to $16 \mathrm{~mm}$ (mean $12 \pm 1.4 \mathrm{~mm}$ ). The follow-up ranged from 1-132 months (mean $27 \pm 24$ months). The gingival index at the last follow-up was 0 for $100(71 \%)$ implants and 1 for 39 (28\%) implants (one implant failed). Crestal bone loss ranged from $0 \mathrm{~mm}$ to $8 \mathrm{~mm}$ : the mean mesial crestal bone loss was $1.09 \pm 0.93 \mathrm{~mm}$, and the mean distal bone loss was $1.07 \pm 1 \mathrm{~mm}$ $(p>0.05)$. The follow-up period was divided into implants with short (i.e., $\leq 36$ months) and long (>36 months) follow-ups. The mesial crestal bone loss was $1.1 \pm 0.7 \mathrm{~mm}$ for the short follow-up period and increased slightly to $1.2 \pm 1.4 \mathrm{~mm}$, for the long follow-up period $(p>0.05)$. The distal crestal bone loss was $1 \pm 0.8 \mathrm{~mm}$ for the short follow-up period and increased slightly to $1.3 \pm 1.5 \mathrm{~mm}$ for the long follow-up period $(p>0.05)$.

\subsubsection{Two-Stage Surgery}

Seventy-four individuals, comprised of 31 (42\%) men and 43 (58\%) women underwent two-stage surgery that involved 253 implants. Their age range was $19-77$ years (mean $55 \pm 13$ years), and 17 (23\%) were current smokers. Of the 253 implants, $118(47 \%)$ were in the lower jaw and $135(53 \%)$ in the upper jaw. The implant diameter ranged from $3.5 \mathrm{~mm}$ to $6 \mathrm{~mm}$ (mean $4.05 \pm 0.4 \mathrm{~mm}$ ), and the implant length ranged from $8 \mathrm{~mm}$ to $16 \mathrm{~mm}$ (mean $12.4 \pm 1.6 \mathrm{~mm}$ ). The follow-up time ranged from 12 to $181 \mathrm{months}$ (mean $41 \pm 42$ months). The gingival index at the last follow-up was 0 for 177 (70\%) implants and 1 for $76(30 \%)$ implants. Crestal bone loss ranged from $0 \mathrm{~mm}$ to $5.28 \mathrm{~mm}$ : the mean mesial crestal bone loss was $0.96 \pm 0.82 \mathrm{~mm}$, and the mean distal bone loss was $0.94 \pm 0.87 \mathrm{~mm}(p>0.05)$. The follow-up period was divided as for one-stage surgery. The mean mesial and distal crestal bone loss for the short follow-up period were both $0.9 \pm 0.7 \mathrm{~mm}$ and increased slightly to $1 \pm 1 \mathrm{~mm}$ and $1.1 \pm 1.1 \mathrm{~mm}$ respectively during the long follow-up $(p>0.05)$.

\subsubsection{One- vs. Two-Stage Procedures}

Table 1 describes the demographics of the two groups. There were no differences between them other than the number of individuals in each group $(40 \%$ more patients in the one-stage group than in the two-stage group), and the number of implants ( $80 \%$ more in the one-stage group than in the two-stage group). The group differences for all the other variables (age, gender, percentage of smokers, implant brand or type, average implant diameter and average implant length) were not significant $(p>0.05)$.

Table 1. Demographic and implant-related data.

\begin{tabular}{ccccccccc}
\hline $\begin{array}{c}\text { Surgical } \\
\text { Technique }\end{array}$ & Patients, $\mathbf{n}$ & Age, $\mathbf{y}$ & \multicolumn{2}{c}{ Gender } & & Implant & $\begin{array}{c}\text { Current } \\
\text { Smokers } \\
\text { (\%) }\end{array}$ \\
\hline Total & $\mathbf{1 1 1}$ & & Male (\%) & Female (\%) & No. & $\begin{array}{c}\text { Diameter } \\
\text { (mm) }\end{array}$ & $\begin{array}{c}\text { Length } \\
\text { (mm) }\end{array}$ \\
\hline $\begin{array}{c}\text { One-stage } \\
\text { Two-stage }\end{array}$ & $52^{*}$ & $54 \pm 14$ & 44 & 56 & 140 & $4.3 \pm 0.5$ & $12 \pm 1.4$ & 15 \\
$p$ & $74^{*}$ & $55 \pm 13$ & 42 & 58 & 253 & $4.05 \pm 0.4$ & $12.4 \pm 1.6$ & 23 \\
& & NS & NS & NS & & NS & NS & NS \\
\hline
\end{tabular}

* 15 individuals were included in both groups (one side single-stage the other side two-stage). The differences were considered significant if $p<0.05$.

\subsubsection{Selection of Surgical Approach}

Figure 1 describes the selection of the surgical method depending on the number of implants that were used. The surgeon chose almost equally the two-stage and the one-stage surgical approaches 
when the number of implants per patient was $\leq 3(54.5 \%$ vs. $45.5 \%$, respectively, $p>0.05)$ and preferred the two-stage surgical approach when the number of implants was $>3$ ( $75.5 \%$ vs. $24.5 \%$, respectively, $p<0.05)$. The choice of surgical approach according to jaw site is depicted in Figure 2.

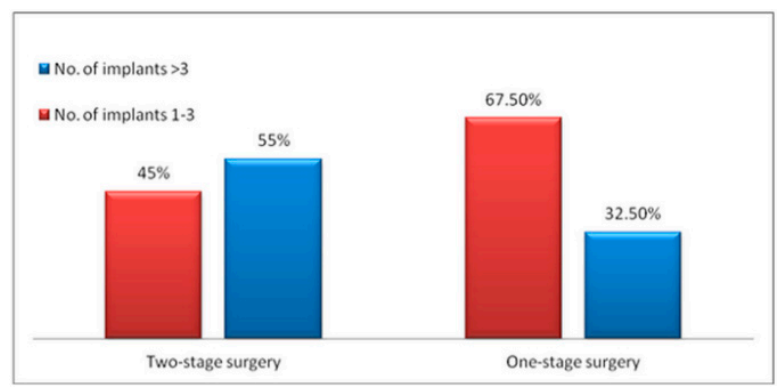

Figure 1. The correlation between the number of implants and the surgical technique.

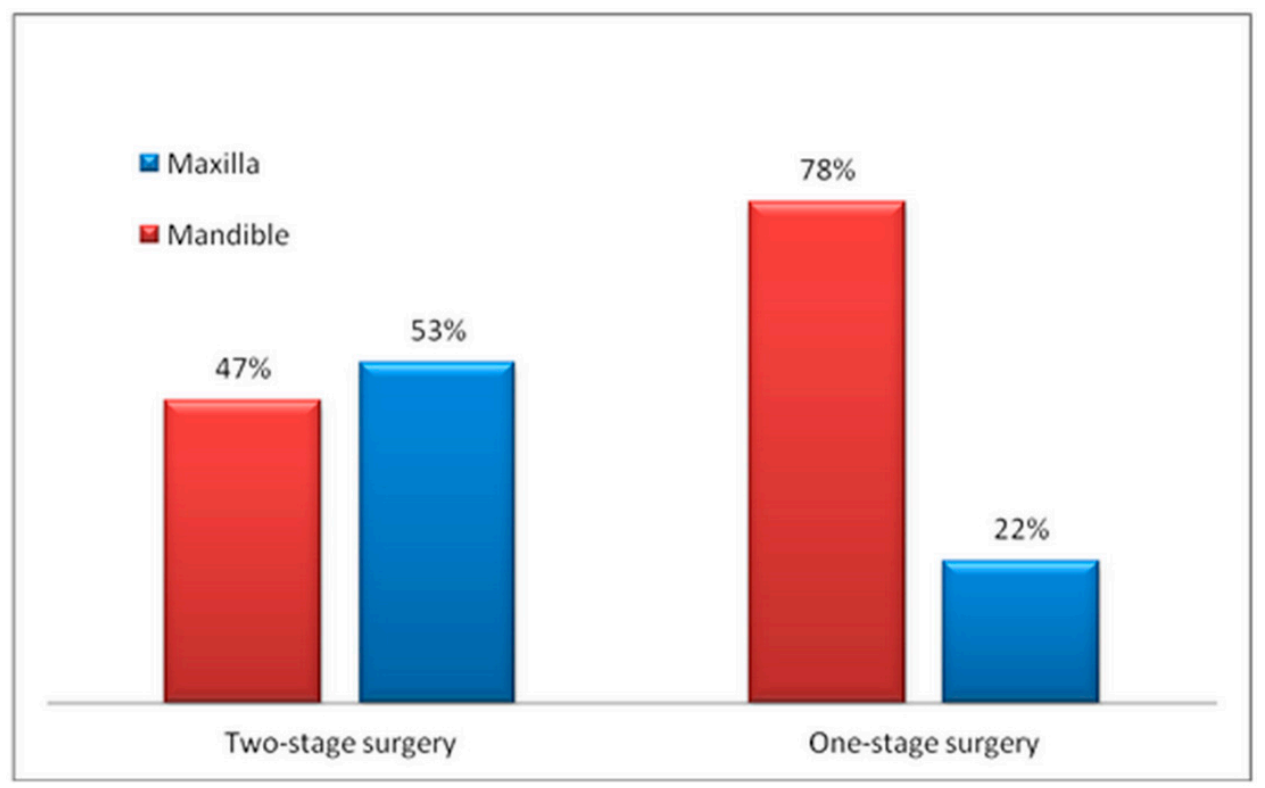

Figure 2. The correlation between maxilla/mandible implant location and the surgical technique.

The one-stage surgical approach was chosen almost equally to the two-stage for the mandible ( $51.9 \%$ vs. $48.2 \%$, respectively, $p>0.05$ ), but the two-stage surgery was chosen almost four times more frequently in the maxilla than the one-stage $(81.8 \%$ vs. $18.2 \%, p<0.05)$.

Table 2 describes the crestal bone loss and the gingival index during the last follow-up. There was no difference in any of these parameters between the two groups either in the short term or the long term. The gingival index results also indicated that oral hygiene was satisfactory for all of the patients in both groups.

Table 2. Comparison of average marginal bone loss and gingival index between the two groups.

\begin{tabular}{|c|c|c|c|c|c|c|c|c|c|c|}
\hline \multirow[t]{2}{*}{$\begin{array}{l}\text { Surgical } \\
\text { Technique }\end{array}$} & \multicolumn{2}{|c|}{$\begin{array}{l}\text { Mesial Marginal } \\
\text { Bone Loss }\end{array}$} & \multirow[t]{2}{*}{$p$} & \multicolumn{2}{|c|}{ Distal Marginal Bone Loss } & \multirow[t]{2}{*}{$p$} & \multicolumn{4}{|c|}{$\begin{array}{c}\text { Gingival Index at Last } \\
\text { Follow-Up }\end{array}$} \\
\hline & $\begin{array}{l}\text { Follow-Up } \\
\leq 36 \text { Months }\end{array}$ & $\begin{array}{l}\text { Follow-Up } \\
>36 \text { Months }\end{array}$ & & $\begin{array}{l}\text { Follow-Up } \\
\leq 36 \text { Months }\end{array}$ & $\begin{array}{l}\text { Follow-Up } \\
\text { >36 Months }\end{array}$ & & 0 & 1 & 2 & 3 \\
\hline One-stage & $1.1 \pm 0.7$ & $1.2 \pm 1.4$ & NS & $1 \pm 0.8$ & $1.3 \pm 1.5$ & NS & $71 \%$ & $28 \%$ & 0 & 0 \\
\hline $\begin{array}{c}\text { Two-stage } \\
p\end{array}$ & $\begin{array}{c}0.9 \pm 0.7 \\
\text { NS }\end{array}$ & $\begin{array}{c}1 \pm 1 \\
\text { NS }\end{array}$ & NS & $\begin{array}{c}0.9 \pm 0.7 \\
\text { NS }\end{array}$ & $\begin{array}{c}1.1 \pm 1.1 \\
\text { NS }\end{array}$ & NS & $70 \%$ & $\begin{array}{r}30 \% \\
\text { NS }\end{array}$ & 0 & 0 \\
\hline
\end{tabular}

The differences were considered significant if $p<0.05$. 
The changing preference of one- vs. two-stage implant procedures over a period of 18 years were as follows respectively-18-16 years 0 vs. $100 \%$; $15-13$ years 0 vs. $100 \% ; 12-10$ years 25 vs. $75 \%$; $9-7$ years 40 vs. $60 \%$; $6-4$ years 35 vs. $65 \%$; $3-1$ years 45 vs. $55 \%$. While none of the implants were placed using a one-stage protocol in the early years, a tendency to switch to one-stage surgery, reaching over $50 \%$, was clearly evident between in the late years.

\section{Discussion}

This long-term retrospective study confirms the results of previous ones that one-stage surgery may yield similar results as those achieved by two-stage surgery [9,17-22] regardless implant brand or type used. In 1996, Barber et al. [9] used a split-mouth design to compare one- vs. two-stage surgery in patients with partial edentulism. Heijdenrijk et al. [11] later conducted a similar comparison of implant-supported overdentures, and Cecchinato et al. [12] compared the two techniques after insertion of implants in the posterior regions of the jaws. The same conclusions were also reached by Becktor et al. [13] Cordaro et al. [14] went one step further and compared the two methods following immediate implantation, and their findings showed similar successful outcome for both methods.

Crestal bone loss in association with one- vs. two-stage surgery was tested in several studies and the results showed no significant differences between the two methods $[11,12,14]$. Those findings are compatible with the results of the current study. There were statistically significant differences in choosing the surgical approach between the mandible and the maxilla. A possible explanation for the increased choice of one stage approach in the mandible, as compared to the maxilla, is the ability to achieve greater initial stability with the insertion of a wider implant into the lower jaw which has a higher density of bone than the upper jaw. It can be speculated that the increased number of implants tipped the decision in the direction of a two-stage in order to reduce risk of failure. When more than three implants are needed, the edentulous area usually requires temporary replacement by a removable appliance. This kind of prosthesis exerts early forces on the underlying implant thus risking their success. Therefore the surgeon preferred covering the implants, and uncover then in a second stage surgery.

It is highly desirable to shorten restorative treatment time, and one-stage surgery fulfills this goal without compromising the long-term clinical results in terms of implant survival and health of the tissue surrounding the implant. One- vs. two-stage implant placement has been a subject of debate. The decision-making process must take into account many factors before a treatment plan can be developed. The data of the present study demonstrated a change of paradigm from two-stage towards one-stage surgery. In 1992-1997, there had been insufficient evidence to support one-stage surgery. The continuous emergence of positive clinical outcome data of one-stage surgery from 1998 up to 2009 and the patients' demand for shortened treatment and fewer surgical procedures may have led to a gradual increase in the prevalence of one-stage surgery from $25 \%$ in 2000 up to $53 \%$ in 2010 [10-14].

Soft tissue parameters need to be considered. The initial incision is less important in two stage surgery. Even if not placed in such a way that allows $2 \mathrm{~mm}$ of keratinized gingiva on either side of the implant, keratinized tissue width can be adjusted at second stage surgery. Whenever one-stage surgery is planned, the initial incision should always be performed being attentive to end the operation with $>2 \mathrm{~mm}$ keratinized soft tissue on buccal and lingual/palatal side of the implant.

One should also consider study limitations as minimizing cofounders by inclusion criteria and similar distribution between groups, the retrospective nature of the study, implant development/changes over the year, and surgeon's preference/bias all of which can influence the results and could not be considered in the present evaluation.

\section{Conclusions}

Lack of long-term differences in implant survival, crestal bone loss and gingival health around implants after one- or two-stage implant placement procedures promoted a significant change over a period of 18 years, increasing the prevalence of one stage-surgery as an evidence-based preferential protocol when there are no specific contraindications. 
Author Contributions: L.C.; S.N.—-data collection and analysis, research design, drafting the paper, approval submission; O.R.; E.Z.; A.G.; D.L.; I.K.; H.Z.: — data collection, drafting the paper, approval submission; G.C.—data analysis, research design, revising the paper, approval submission; J.N.- data analysis, research design, revising the paper, approval submission. All authors have read and agreed to the published version of the manuscript.

Funding: The study received no funding.

Acknowledgments: Yaron Sela, Research statistical consultant, $p$-value VOD, $p$-value-VOD.co.il.

Conflicts of Interest: The authors declare no conflict of interest.

\section{References}

1. Brånemark, P.I.; Hansson, B.O.; Adell, R.; Breine, U.; Lindström, J.; Hallén, O.; Ohmanet, A. Osseointegrated implants in the treatment of the edentulous jaw. Experience from a 10-year period. Scand. J. Plast. Reconstr. Surg. 1997, 16, 1-132.

2. Esposito, M.; Grusovin, M.G.; Chew, Y.S.; Coulthard, P.; Worthington, H.V. Interventions for replacing missing teeth: 1- versus 2-stage implant placement. Cochrane Database Syst. Rev. 2009, 3, CD006698. [CrossRef] [PubMed]

3. Albrektsson, T.; Brånemark, P.I.; Hansson, H.A.; Lindström, J. Osseointegrated titanium implants. Requirements for ensuring a long-lasting, direct bone-to-implant anchorage in man. Acta. Orthop. Scand. 1981, 52, 155-170. [CrossRef] [PubMed]

4. Brunski, J.B.; Moccia, A.F.; Pollack, S.R.; Korostoff, E.; Trachtenberg, D.I. The influence of functional use of endosseous dental implants on the tissue-implant interface. I. Histological aspects. J. Dent. Res. 1979, 58, 1953-1969. [CrossRef]

5. Buser, D.A.; Schroeder, A.; Sutter, F.; Lang, N.P. The new concept of ITI hollow-cylinder and hollow-screw implants: Part 2. Clinical aspects, indications, and early clinical results. Int. J. Oral Maxillofac. Implants 1988, 3, 173-181.

6. Buser, D.; Weber, H.P.; Lang, N.P. Tissue integration of non-submerged implants. 1-year results of a prospective study with 100 ITI hollow-cylinder and hollow-screw implants. Clin. Oral Implants Res. 1990, 1, 33-40. [CrossRef]

7. Buser, D.; Mericske-Stern, R.; Bernard, J.P.; Behneke, A.; Behneke, N.; Hirt, H.P.; Belser, U.C.; Lang, N.P. Long-term evaluation of non-submerged ITI implants. Part 1: 8-year life table analysis of a prospective multi-center study with 2359 implants. Clin. Oral Implants Res. 1997, 8, 161-172. [CrossRef]

8. Ericsson, I.; Randow, K.; Nilner, K.; Petersson, A. Some clinical and radiographical features of submerged and non-submerged titanium implants. A 5-year follow-up study. Clin. Oral Implants Res. 1997, 8, 422-426. [CrossRef]

9. Barber, H.D.; Seckinger, R.J.; Silverstein, K.; Abughazaleh, K. Comparison of soft tissue healing and osseointegration of IMZ implants placed in one-stage and two-stage techniques: A pilot study. Implant Dent. 1996, 5, 11-14. [CrossRef]

10. Collaert, B.; De Bruyn, H. Comparison of Brånemark fixture integration and short-term survival using one-stage or two-stage surgery in completely and partially edentulous mandibles. Clin. Oral Implants Res. 1998, 9, 131-135. [CrossRef]

11. Heydenrijk, K.; Raghoebar, G.M.; Meijer, H.J.A.; Van Der Reijden, W.A.; Van Winkelhoff, A.J.; Stegenga, B. Two-part implants inserted in a one-stage or a two-stage procedure. A prospective comparative study. J. Clin. Periodontol. 2002, 29, 901-909. [CrossRef] [PubMed]

12. Cecchinato, D.; Olsson, C.; Lindhe, J. Submerged or non-submerged healing of endosseous implants to be used in the rehabilitation of partially dentate patients. A multicenter, randomized controlled clinical trial. J. Clin. Periodontol. 2004, 31, 299-308. [CrossRef]

13. Becktor, J.P.; Isaksson, S.; Billström, C. A prospective multicenter study using two different surgical approaches in the mandible with turned brånemark implants: Conventional loading using fixed prostheses. Clin. Implant Dent. Relat. Res. 2007, 9, 179-185. [CrossRef] [PubMed]

14. Cordaro, L.; Torsello, F.; Roccuzzo, M. Clinical outcome of submerged vs. non-submerged implants placed in fresh extraction sockets. Clin. Oral Implants Res. 2009, 20, 1307-1313. [CrossRef] [PubMed]

15. Löe, H. The gingival index, the plaque index and the retention index systems. J. Periodontol. 1967, 38, 610-616. [CrossRef] 
16. Turkyilmaz, I.; Sennerby, L.; Tumer, C.; Yenigul, M.; Avci, M. Stability and marginal bone level measurements of unsplinted implants used for mandibular overdentures: A 1-year randomized prospective clinical study comparing early and conventional loading protocols. Clin. Oral Implants Res. 2006, 17, 501-505. [CrossRef]

17. De Smet, E.; Jacobs, R.; Gijbels, F.; Naert, I. The accuracy and reliability of radiographic methods for the assessment of marginal bone level around oral implants. Dentomaxillofac. Radiol. 2002, 31, 176-181. [CrossRef]

18. Batenburg, R.H.; Meijer, H.J.; Geraets, W.G.; van der Stelt, P.F. Radiographic assessment of changes in marginal bone around endosseous implants supporting mandibular overdentures. Dentomaxillofac. Radiol. 1998, 27, 221-224. [CrossRef]

19. Batenburg, R.H.; Meijer, H.J.; Raghoebar, G.M.; Van Oort, R.P.; Boering, G. Mandibular overdentures supported by two Brånemark, IMZ or ITI implants. A prospective comparative preliminary study: One-year results. Clin. Oral Implants Res. 1998, 9, 374-383. [CrossRef]

20. Cox, J.F.; Zarb, G.A. The longitudinal clinical efficacy of osseointegrated dental implants: A 3-year report. Int. J. Oral Maxillofac. Implants 1987, 2, 91-100.

21. Ericsson, I.; Randow, K.; Glantz, P.O.; Lindhe, J.; Nilner, K. Clinical and radiographical features of submerged and nonsubmerged titanium implants. Clin. Oral Implants Res. 1994, 5, 185-189. [CrossRef] [PubMed]

22. Bernard, J.P.; Belser, U.C.; Martinet, J.P.; Borgis, S.A. Osseointegration of Brånemark fixtures using a single-step operating technique. A preliminary prospective one-year study in the edentulous mandible. Clin. Oral Implants Res. 1995, 6, 122-129. [CrossRef] [PubMed]

(C) 2020 by the authors. Licensee MDPI, Basel, Switzerland. This article is an open access article distributed under the terms and conditions of the Creative Commons Attribution (CC BY) license (http://creativecommons.org/licenses/by/4.0/). 